\title{
Validation of Real Case Solving (RCS) Methodology as an Efficient Engineering Learning Tool
}

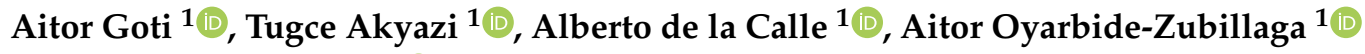 \\ and Elisabete Alberdi $2, * \mathbb{D}$ \\ 1 Department of Mechanics, Design and Industrial Organization, University of Deusto, 48007 Bilbao, Spain; \\ aitor.goti@deusto.es (A.G.); tugceakyazi@deusto.es (T.A.); acalle@deusto.es (A.d.1.C.); \\ aitor.oyarbide@deusto.es (A.O.-Z.) \\ 2 Department of Applied Mathematics, University of the Basque Country UPV/EHU, 48013 Bilbao, Spain \\ * Correspondence: elisabete.alberdi@ehu.eus
}

Received: 20 November 2020; Accepted: 17 December 2020; Published: 19 December 2020

\begin{abstract}
In recent times, new learning methodologies known as student-based methodologies have been introduced to simplify the learning process for the students and facilitate the acquisition of skills for them. Among them, problem based learning (PBL) and project-based learning (PjBL) are widely used methods in the world of education. Real case solving (RCS) is a variant of the PBL where students solve real cases through the application of the PBL methodology. RCS seems to be a relevant approach for educators, but it has an apparently limited implementation degree at the academic level. This article presents the successful implementation of four different RCS approaches in the lecturing process in five different classes in the engineering degree of University of Deusto. The initiative has been analyzed both quantitative and qualitatively; the overall performance and success rate of the students were compared with the ones acquired from conventional teaching methods. The results were found to be promising, demonstrating a significantly better performance than the traditional teaching methodologies. The successful results encouraged the university to continue working further in this direction.
\end{abstract}

Keywords: real case solving; problem based learning; simulation; education; engineering

\section{Introduction}

A wide variety of learning methodologies have recently been developed to enable and simplify the acquisition of skills. Among them, student centered methodologies where learning is based on tasks, games, problems, projects, challenges, case studies, etc. stand out as having successful results for meaningful learning. These methodologies aim to construct the provision of an active process of knowledge construction through keeping the students' attention, emphasizing their independence and inquiry, and, in the last term, improving their pass rates.

Some of these methodologies can also be used interchangeably such as in the case of project-based learning (PjBL) and problem based learning (PBL) methods. Larmet et al. explained the substantial differences between the two methods in order to make it easier to use them accurately: PjBL has a wider and a more complex scope and often includes the design and creation of a product, and requires a multi-disciplinary and multi-subject approach, while PBL is more specific and is often based on a single-subject [1]. PjBL may use scenarios, but often involves real world, fully authentic tasks and settings, while PBL often uses fictitious scenarios as "illustrated problems" or real-life situations that correspond to real case studies. Barrows et al. defined PBL as a direct result of the learning process to understand or solve a problem [2], whereas Surif et al. considered it as a first step, since through the process, the students are encouraged to find new information and organize existing knowledge [3]. 
In any case, the effectiveness of both the PjBL and PBL methods has been continuously demonstrated (e.g., Zhang et al. scientifically proved that the PBL model yielded higher course examination pass rates, excellence rates, and examination scores) [4].

It has been shown that active learning increases student performance during undergraduate degrees [5]. A recent study states that the impact of PjBL on student academic achievement is not affected by educational stage [6], however, at higher education levels, there is a claim for conducting more studies to evaluate student learning processes and the performance of these methods [7]. Nevertheless, it is already clear that the use of real cases has a greater impact on actively engaging students in the learning process and makes it easier for students to be aware of the application and relevance of the subject in the real world $[5,8]$.

Its scope neither focuses only on technical knowledge nor has a short-term impact. How students approach these methods enhances their work-related skills such as autonomy, responsibility, team building, and communication [9]. At the same time, they build up abilities in the project management area, which are particularly interesting for the project-based global economy, and also for fostering innovation capabilities [10]. As a result, the students improve their employability [11].

Additionally, PjBL/PBL methodologies aim to enhance "self-directed learning" skills by changing the usual lecturer role of teachers toward a mentoring role. Gal et al. pointed out that teachers' roles are still essential for participatory methodologies through this role change and that their appreciation by students can dramatically change when teachers assume a mentoring role [12]. It would also be interesting to have people from companies take part in mentoring students as they can provide a real world point of view to the work done in the subjects.

The real case solving (RCS) methodology is mostly based on the single subject PBL model, but proposes the resolution of an actual problem or case. The traditional PBL approach is complemented with seminars of sectorial managers who come to class to seek possible solutions for an actual problem. The guidance of experts in the area with the support of lecturers in a mentor role highly increases the interest on the topic. Through these projects, the students use their knowledge to solve real problems within the context of their future professional area. Linking university teaching to real industry needs, as [1] suggests. Thus, it is possible to motivate students through demonstrating to them the real applications of those theoretical concepts, which have been previously explained in class. As a consequence, and among others, RCS can be considered a successful methodology to improve the educational process.

Although the RCS approach has a theoretical inherent attractiveness [13], the literature available regarding the subject is relatively scarce, specifically regarding engineering education. Some of the engineering education areas or specific topics covered by the existing literature are design [14], supply chain management $[15,16]$, computing education $[17,18]$, civil engineering education $[19,20]$, and industrial engineering [21]. Finally, Fernández et al. demonstrated a RCS implementation to the subjects related to information and communication technologies (ICTs) [22].

The RCS methodology varies slightly in each of the mentioned implementations. In this work, we adopted the methodology proposed by Fernández et al. [22]. The methodology considered the following processes, tools, and outputs:

- Theoretical classes to address basic knowledge along with resolution of real cases related to the topic of a particular project.

- Project or problem presentations.

- Seminars given by an expert on the related area.

- Short tests about basic concepts related to the subject.

- A platform to integrate everyone involved in the project, and to exchange information (text, glossaries, videos, etc.). This platform was based on Moodle (http://moodle.org/), an educational resource management platform, which hosts a forum for groups.

- Production of the evaluation methods that will be used to assess the projects, and sharing them with the students. 
- Doubt clarification, mostly through tutoring. Professors and lecturers supervising the work on a systematic and periodic basis.

- Surveys, which are carried out along the whole course to track student evolution and to elaborate statistics. Partial results will be taken into account for the approach of the next project.

A final report that is to be delivered at the end of the process including a complete statistical analysis. In this work, we present a detailed analysis about the implementation of the RCS approach applied to the lectures at the Engineering Faculty of the University of Deusto with the aim of checking if RCS is a significantly better teaching methodology compared to the methods and tools taught in the rest of the subjects. Thus, the questions for this research were: (i) Are RCS tasks stimulating?, (ii) Do they stimulate the generation of ideas?, (iii) Does the methodology support the autonomy of the student?, and (iv) Does the methodology make students reflect on the learning experience?

To respond to these questions, four different RCS projects were launched and applied to the lecturing process in five different classes (one of the RCS approaches was applied in two classes, and thus we obtained five cases) and the overall performance and success rate of students were compared with the ones acquired from conventional teaching methods.

To make the comparison, we used the general questionnaire students fill in at the University of Deusto for the evaluation of a subject. The University of Deusto, like many other universities, uses anonymous questionnaires to be filled in by students to evaluate the correct development of subjects. The questionnaire was developed under the principles of the DOCENTIA program, which is promoted by the National Agency for Quality Assessment and Accreditation of Spain (ANECA), as a means of guaranteeing the quality of the teaching activity carried out by the teaching staff. DOCENTIA assesses their teaching competence by evaluating how they plan, develop, value, and improve their teaching. Being a highly consolidated tool at the University of Deusto, the authors considered it appropriate and robust enough to conduct this research.

The results were found to be promising, demonstrating significantly better performances than the traditional teaching methodologies. The rest of this paper is organized as follows. Section 2 introduces the real cases to develop RSC methodology and gives detailed information about the implementation process. Then, it explains how the presented real cases were turned into didactic material in order to be used as RCS cases in lecturing classes. Section 3 details both the qualitative and statistic results of the application of the RCS cases, whereas Section 4 summarizes the most significant concluding remarks and comments on the short- and mid-term future orientations of the research.

\section{Presentation of the Real Case Solving (RCS) Cases}

In this section, we describe four real cases that were used to develop RCS methodologies. The four cases were studied in five full classes of four different subjects, different academic courses, and different degrees. These subjects must be passed to develop specific and generic competences defined at the subject syllabuses and are needed to complete the future professional profile of the student of each degree. It is essential to remark that each of these full classes had one RCS subject and other four or five subjects taught using conventional methods, and that the statistical comparison presented herein was made between the RCS subjects against the rest of the subjects. The four classes mentioned above are:

- Class 1: Technical office.

- Class 2: Management of companies.

- Class 3: Management of processes through Enterprise Resource Planning (ERP) information systems.

- Class 4 and 5: Modeling and simulation of industrial processes (with two different groups).

The four cases were based on the process of turning several research projects into educational materials. These projects are co-funded with public and private funds, and the results were published in journals indexed at the Journal Citation Reports database (JCR). The cases can be described as follows:

Case 1 Implementing a Business Intelligence (BI) tool for maximizing the impact of a publication included at JCR list; 
Case 2 Implementing a BI tool for obtaining micro and macro Key Performance Indicators (KPIs) for managing the production costs of a business;

Case 3 Obtaining the optimal reordering point of items considering backlog, storage, and ordering cost by the use of simulation techniques; and

Case 4 Optimizing the amount of supermarket cashiers depending on the demand patterns.

Finally, it is worth remarking that:

- Class 1 developed Case 1,

- Class 2 solved Case 1 as well as Case 2,

- Class 3 implemented Case 2, and finally,

- Class 4 and Class 5 elucidated Cases 3 and 4.

Each of the cases is detailed in the following sub-sections.

\subsection{Case 1: Implementation of a BI Tool for Maximizing the Impact of a Publication}

The first case was based on a project co-founded by the Department of Education of the Basque Government (University Company call, UE2016-10 project code). The results were shown by Goti et al. [23].

The work aimed at implementing a Business Intelligence (BI) tool at the DYNA journal (ISSN: 0012-7361, ISSN digital: 1989-1490 and DOI:10.6036/DYNAII). The objective of the research was to identify the most influencing elements on the improvement of the Journal Impact Factor.

Concerning BIs, it is worth noting that BI systems include applications, infrastructure, tools, and best practices that allow access and analysis of information to improve both the decision-making process and its impact. Parenteau et al. and Shukla et al. define BI systems as a set of techniques and tools for processing and transforming, within seconds, large amounts of raw data into consistent, visual, and useful information for business analysis [24,25]. As Kerschberg et al. indicate, BI systems are changing business and industry. The latest technological developments have promoted the use of BI systems for the improvement and optimization of decision making processes in both agility and performance terms [26].

The scientific publication sector demands more efficiency and improvement in business models as well as other sectors. As in Case 1, we introduced a BI development project regarding a scientific journal (DYNA) to a group of students and expected them to develop prototypes of solutions to companies in a PBL environment. In this specific RCS case, the initial input was an anonymized copy of the article management database (publications) used by the editor of the journal, in Microsoft Access ${ }^{\circledR}$ format. The database included information regarding authors, articles, evaluators, evaluations, acceptance/rejections, and evaluations. In addition to the anonymized image of the local database, all the information regarding the DYNA articles that were historically cited in the JCR and the SJR was integrated into Microsoft Excel ${ }^{\circledR}$ spreadsheets. The integrated information consisted of several data such as who cited what article, in which journal and when, etc. In order to incorporate all the mentioned data, a free and educational version of Qlikview ${ }^{\circledR}$ was used as the BI system; the BI read all the origins and established a proposal for an editable relational model of data (shown in Figure 1). This proposal included all the requirements to extract and visualize the information and generated it in the format required by the client (editorial board) to facilitate the decision-making process. 


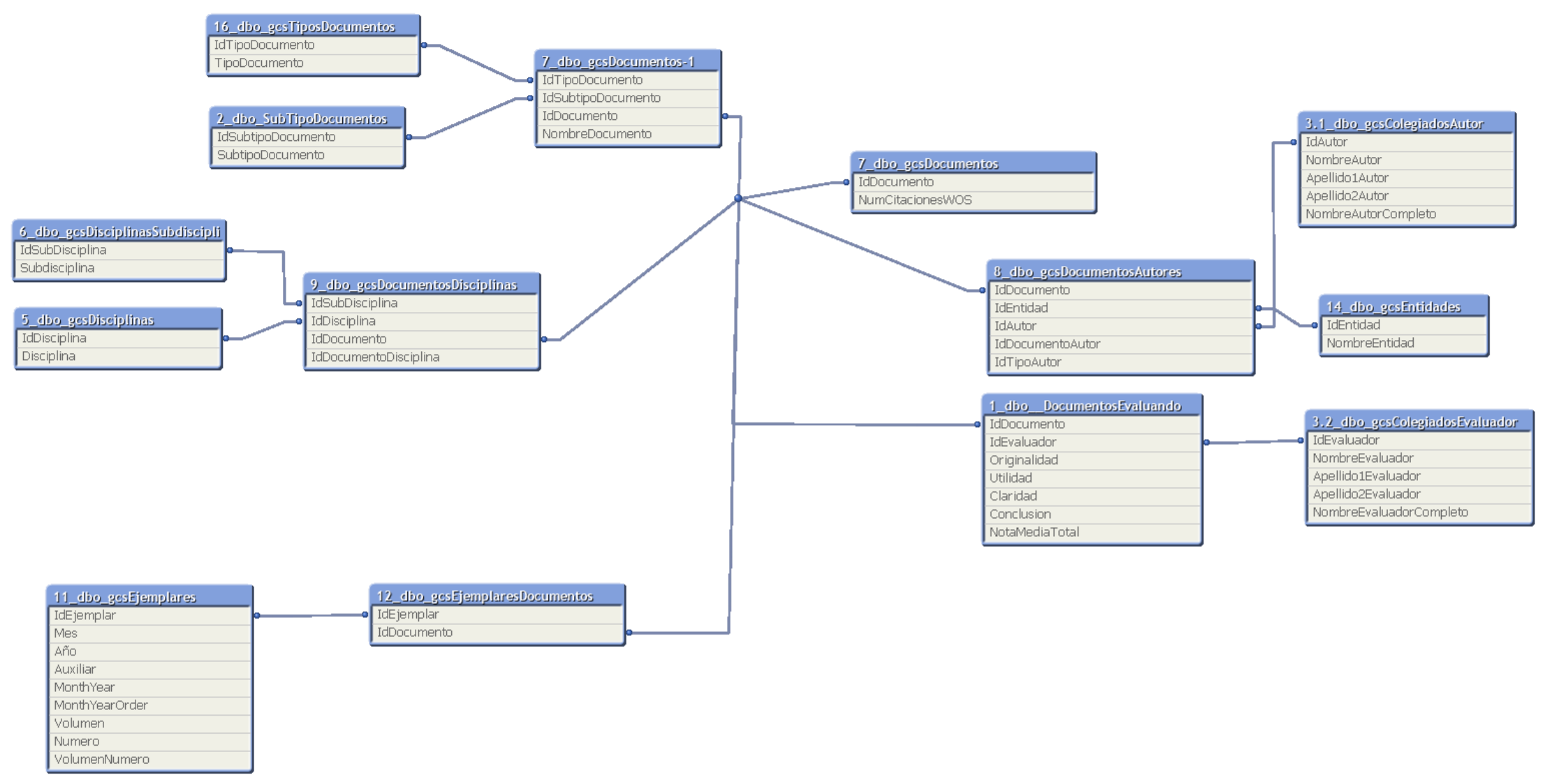

Figure 1. Data model automatically developed by the BI system in the process of reading the data sources [23]. 
The students designed a series of screens on the model incorporating the information and format required by the client. This solution allowed them to visualize and analyze the information in order to improve the impact and visibility of the Journal. For example, Figure 2 demonstrates a visualization of the disciplines and sub-disciplines of the journal that have received the most significant amount of JCR citations (larger area indicates a higher number of records).

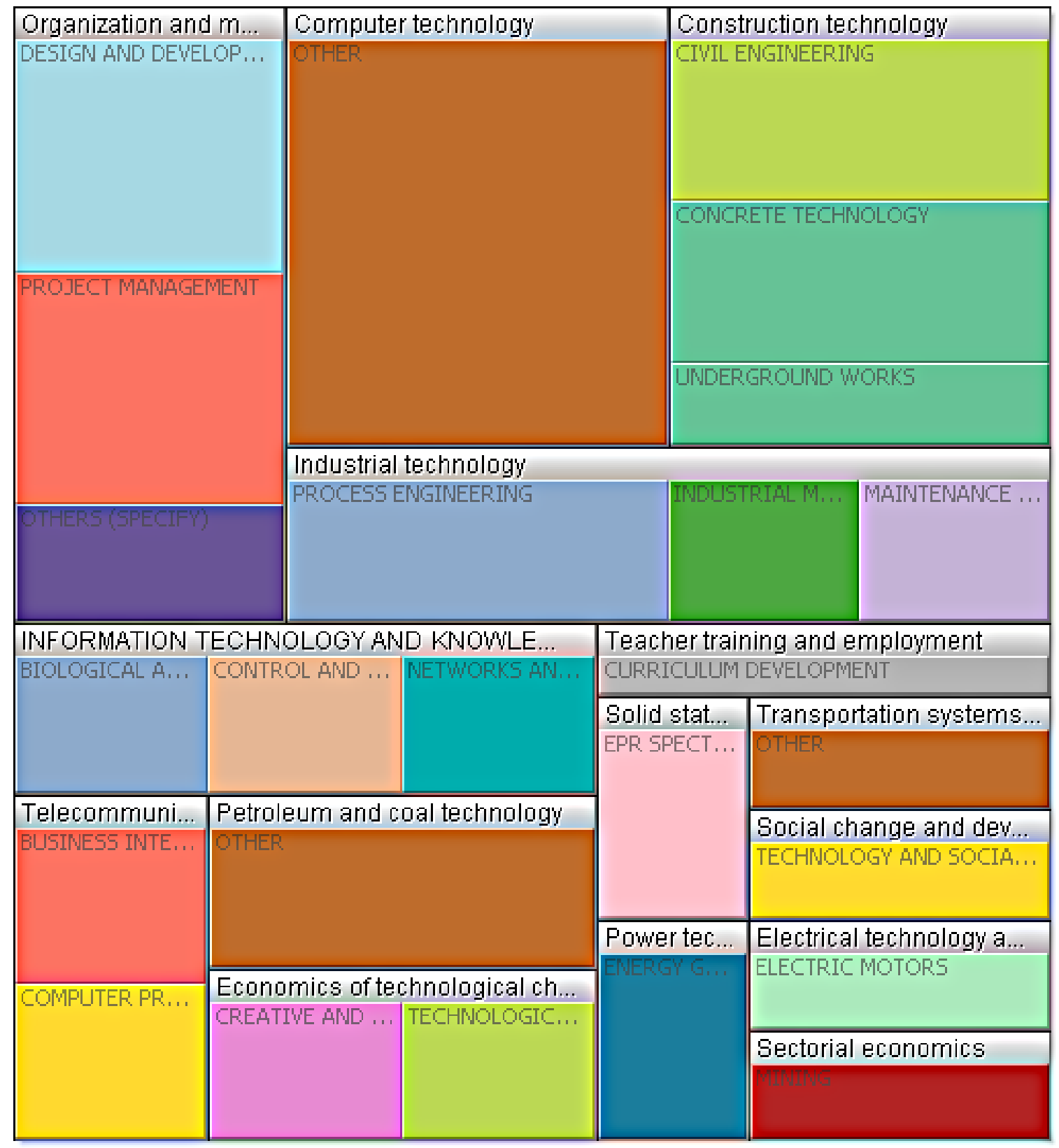

Figure 2. Diagram of the JCR impact obtained by each of the disciplines and sub-disciplines of the DYNA Journal [27].

Thanks to the developed visualization panels, it was possible to identify:

- Areas of knowledge that are more likely to receive more appointments,

- Authors who are more likely to receive more citations, and

- Reviewers who evaluate an article favorably and are likely to obtain articles that will receive more citations afterward. 


\subsection{Case 2: Implementation of a BI Tool for Obtaining Micro and Macro KPIs for Managing the Production} Costs of a Business

The second case took the very same project as a basis as in the first real case: the project was co-founded by the Department of Education of the Basque Government (University Company call, UE2016-10 project code) and the results were shown by Goti et al. [23]. The presented case was a simplified version of an implementation of a BI system in a food industrial environment with Big Data features, in which data from multiple sources are incorporated to provide information in order to improve decision-making.

While preparing the real case for the RSC method, the case presented in the project was modified (in order to simplify) and anonymized (for confidentiality). It focused on the development of a production control BI for one of the production plants. Therefore, the information coming from two data sources was combined. The first data source was the batching system (managed by a specific software) and the second one was the input of the produced finished goods (generated automatically with enterprise resource planning (ERP) software through printing a sticker declaring the finalization of each finished good). As a result, students could obtain the data automatically such as labor costs of a product or employees that had produced a specific (defective) batch, etc.

The BI system is able to integrate these different data sources in depth and to build an entity-relationship model. This integration enables, as shown in the next section, the ability to display information that is difficult to obtain in other ways.

In this case, BI enables the two tables to have a common denominator for production line and date fields, proving that it is possible to obtain combined information from both sources. As a result, it was possible to obtain a dynamic scorecard that enables filtering and getting any data from the filtered area of the BI screen. The tool displays information such as:

- Number of units manufactured in a production line in a certain time interval (see Figure 3):

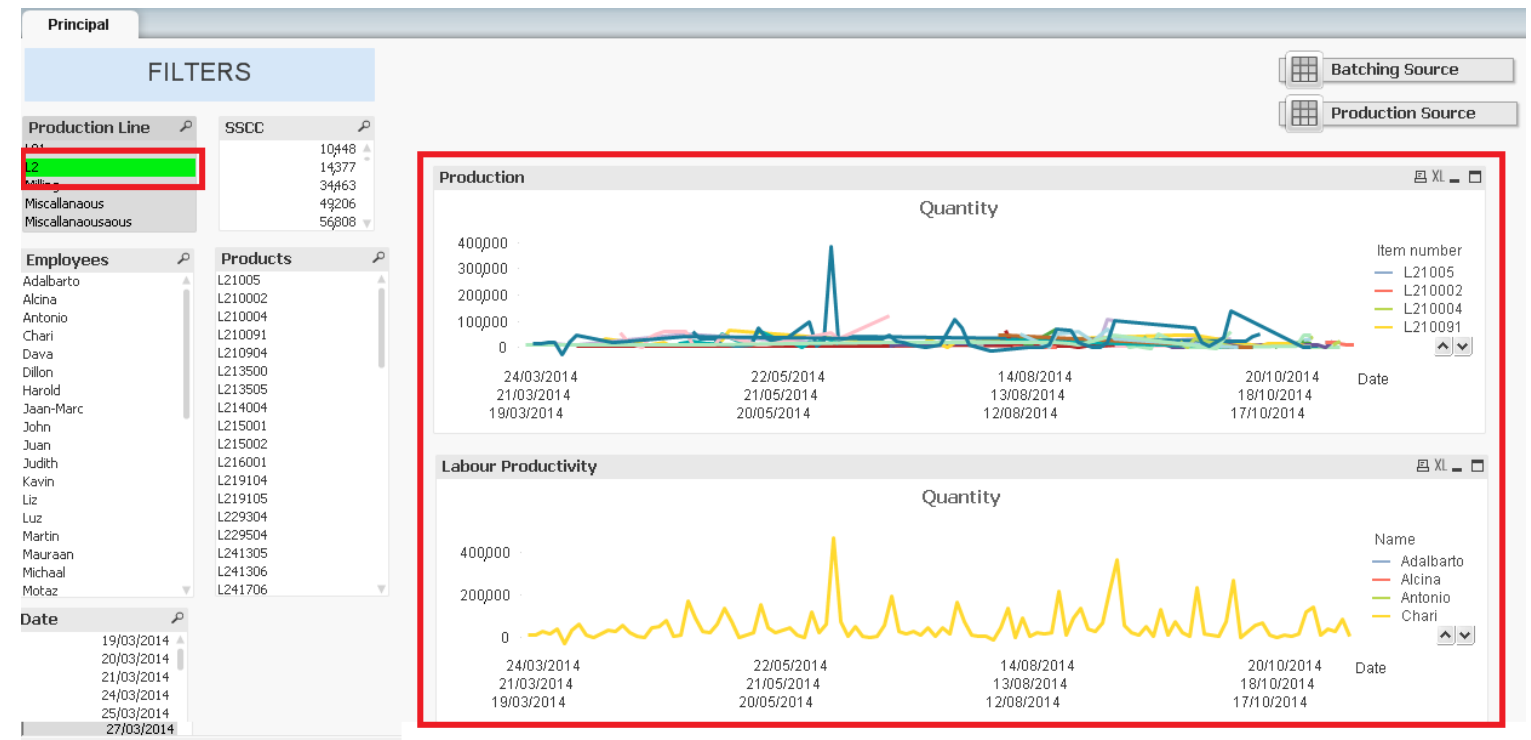

Figure 3. Comparative graph of units produced per line, employee, product, and day.

- The unitary traceability of the products, which allows us to indicate the personnel that generates the product. In Figure 4, the pallet number, also named SSCC, the name of employees who contributed to the production, production line where the product was manufactured, and production date can be shown to trace the product and have the whole history. 


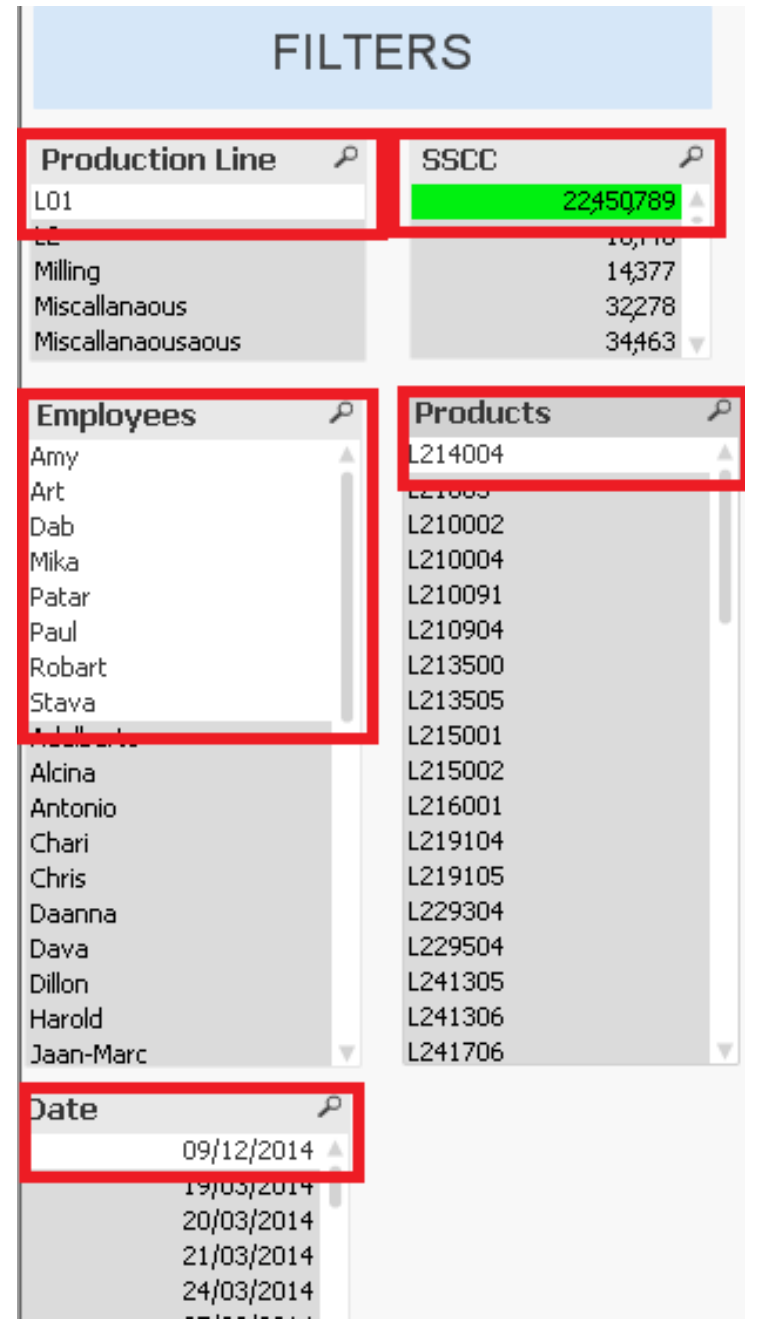

Figure 4. Unitary traceability of the product.

- Number of units produced per employee in a certain period of time and thus, labor productivity (see Figure 5).

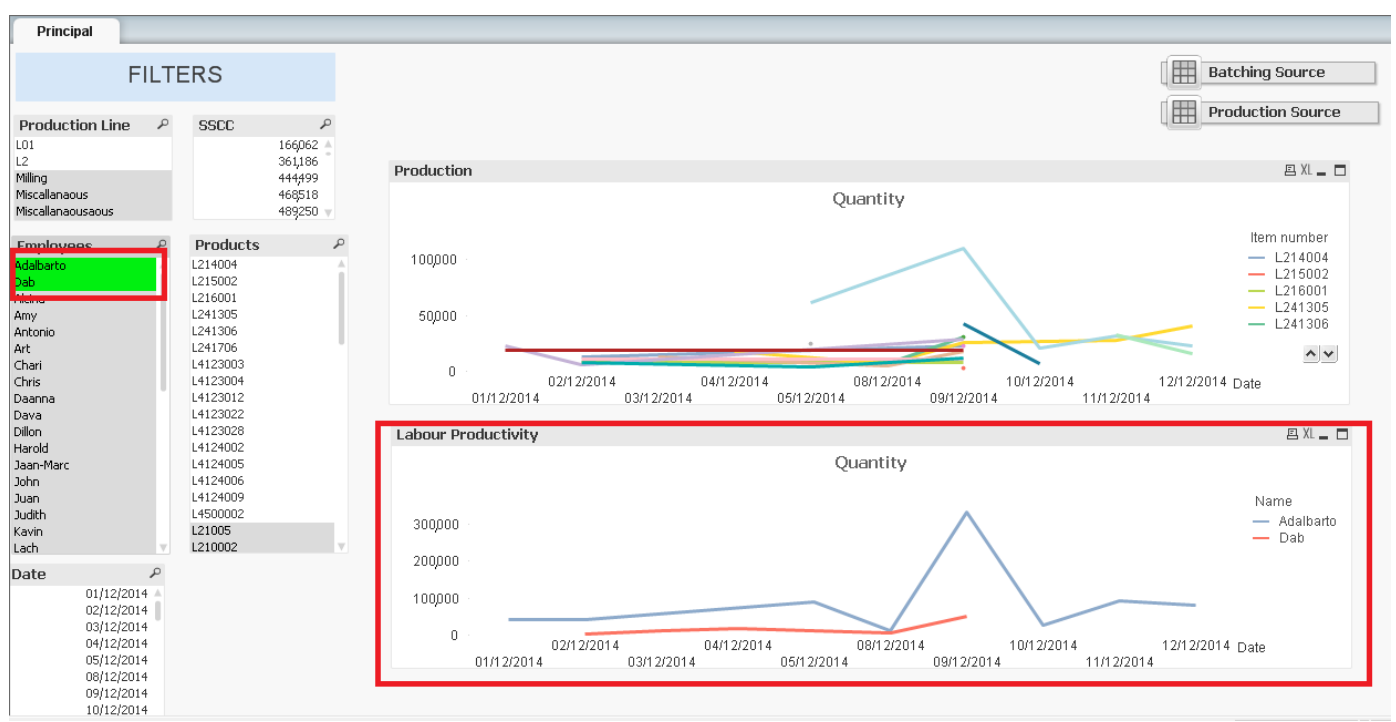

Figure 5. Comparative graph showing the labor productivity. 
Therefore, in the described case, students experienced that the implementation of the BI tool enabled and accelerated data collection and analysis, reducing uncertainty, and providing evidence for decision-processes. Additionally, students understood the importance and the relevance of gaining knowledge in the development of such solutions. The method that was used to solve this case can be applied to many other areas where data needs to be analyzed. Therefore, it was a valuable addition to the students' knowledge.

\subsection{Case 3: Optimization of Reordering Points of Items Considering Backlog, Storage, and Ordering Cost}

The third real case generated for the RCS was based on a project co-founded by the following national and transnational projects: Department of Education of the Basque Government-Basic and Applied Research call, University Company call with PI2009-24 project code, and Transnational Manunet Calls with MANUNET-2008-BC-001 and MANUNET-2009-BC-006 project codes. The results were published by Goti et al. and Parentau et al. [24,28].

Regarding the RCS, it can be concluded that most companies implement lean production principles, mostly related to waste-minimization due to unnecessary or unneeded and inefficient operations (such as excessive buffering operations to serve the client or backorders) [29].

Considering this background information and the context conditions, students developed a single input variable optimization in order to find the optimal reordering points. The assumptions and output objectives are explained in Figure 6 and described below.

\section{Input Data}

\begin{tabular}{|lr|}
\hline ReorderingPoint & 20 \\
LotSize & 50 \\
LeadTime & 2.56 \\
DemandD & 12 \\
\hline
\end{tabular}

\section{Output Data}

\begin{tabular}{|llll|}
\hline No. Orders & 2 & OrderingCost & $\mathbf{2 5 0 . 0 0}$ \\
Average Stock x Time & 20 & HoldingCost & $\mathbf{2 3 3 . 6 2}$ \\
Non-met demand & 41 & BackOrderCost & $\mathbf{4 1 0 . 0 0}$ \\
& & TotalCost & $\mathbf{8 9 3 . 6 2}$ \\
\hline
\end{tabular}

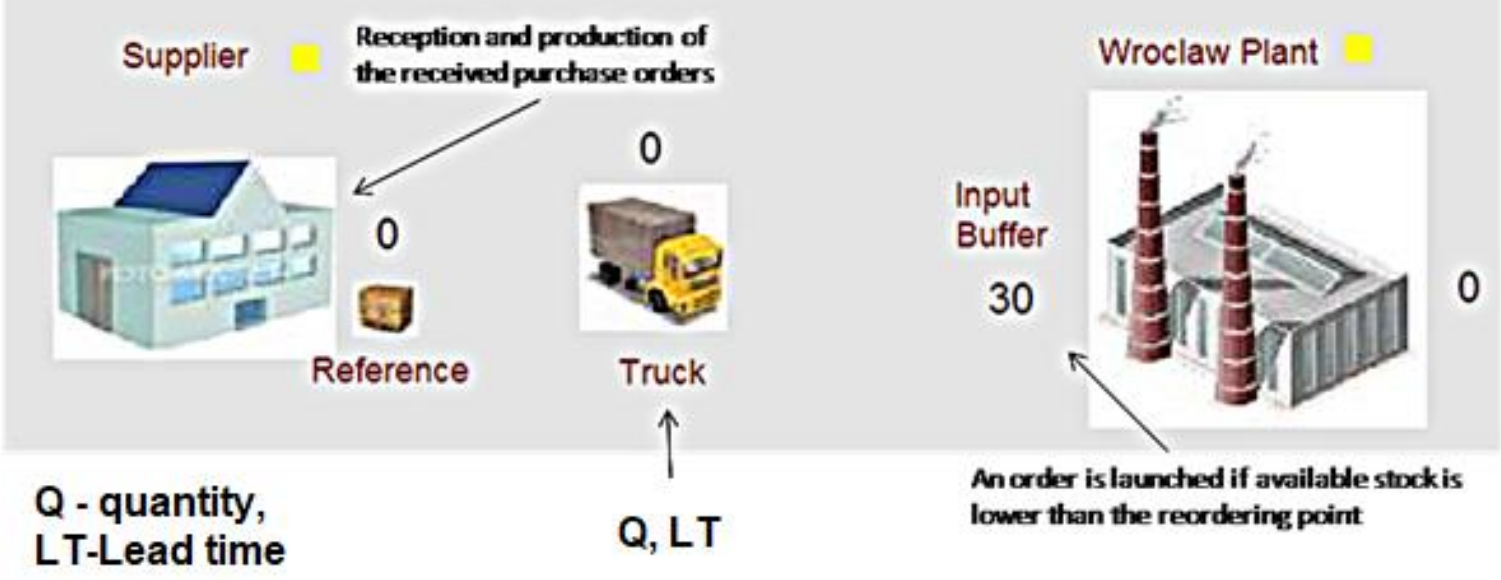

Figure 6. Graphical description of the reordering problem to be solved.

- For the developed RCS, these assumptions were taken into account.

- The logistic lead time-time for a purchase order-was submitted to the arrival of the products related to that order. This was variable, but known (historical data were available, so that information could be integrated into a known distribution).

- The customer demand rate of the client, in other words, the speed that the client consumed buffered products was known (historical data was available, so that information could be integrated into a known distribution). 
- The buffer that contained the arriving products had an infinite capacity.

- Each batch of products that were bought jointly had a fixed purchasing order cost.

- Each product had a fixed cost per unit of time for being stored in a buffer.

- A fixed backorder cost was assigned each time a client needed to take a product from the buffer and did not find any products within the buffer.

Finally, in order to optimize the outcomes, the students had to consider the joint minimization of the total cost for (i) submitting purchase orders, (ii) receiving them at the plant warehouse, (iii) holding and storing elements in the buffer, and (iv) not serving the client because the buffer was empty.

Discrete event simulation (DES) was used as the modeling technique for this RCS. DES dynamically models the operation of a system as a discrete sequence of events. It alters the state of the model only when events occur, so that it does not waste computational time simulating intervals of time when the system remains the same. DES has two main advantages: (i) standard DES-based tools provide modeling capabilities or facilitates modifying complex system models easily, and (ii) DES is closely related to stochastic systems, which are appropriate for simulating real world phenomena [30]. In order to generate stochastic events, simulation packages generate pseudo-random numbers to select a particular value for a given distribution. Thus, in DES models, it is possible to implement the stochastic nature of the actual spare part and consumable consumption models through using pseudo-random numbers. In this work, the development of the model was performed using an educational version of Witness (Lanner ${ }^{\circledR}$, England, UK), where the total cost calculation was generated by multiplying the times an event related to the above-mentioned costs happened by its concept of cost. As the optimization technique for RSC, the brute force technique (calculation of all possible choices within a range) was used since the aim of the subject was not to get deep into optimization algorithms.

\subsection{Case 4: Optimizing the Amount of Supermarket Cashiers Depending on the Demand Patterns}

The cashier optimization problem is a rather classical problem in the area of quantitative methods. Some of the authors of the study introduced by Melachrinoudis and Olafsson et al. worked in the past for a Basque retail company to solve a similar problem [31]. In this developed case, the students had to model a simplified mall with the following assumptions:

- The number of customers that came to the mall was calculated by the rate of "customers/hour", which is different every hour of the day.

- When customers wanted to leave the mall, the supermarket tried to serve them ASAP. As a rule of the supermarket, when there were five customers in line, one additional checkout was opened, but customers could not change their waiting lines once they were already in one.

- The supermarket was open $12 \mathrm{~h} /$ day for six days a week. To simplify the model, it was assumed that the supermarket worked non-stop for $72 \mathrm{~h}$ per week.

- The availability of boxes was assumed to be unlimited, however, due to software version restrictions, it was simulated with a maximum of seven supermarket checkouts. Each checkout had an associated cashier that would be available $100 \%$ of the time.

- To import data and collect results, the model interacted with Excel.

The simulated number of customers per hour for the whole week is shown in Figure 7. 


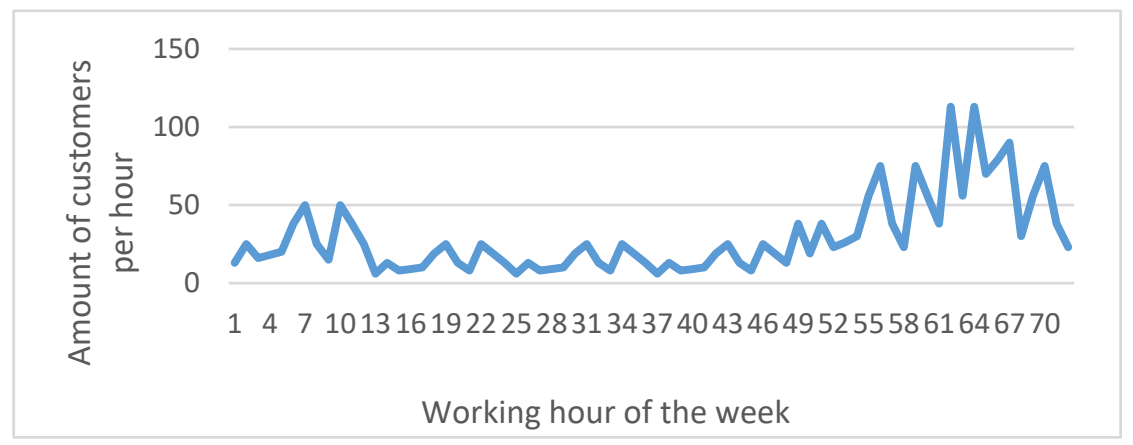

Figure 7. Simulated number of customers per hour for the whole week.

As in previous cases, this RCS was successfully solved, in this specific case, using DES.

\section{Results and Discussion}

As stated at the end of Section 1, the effectiveness of the RCS tool was measured using the general questionnaire the university uses for evaluating the performance of its subjects. An analysis was performed to verify if the results obtained using RCS were statistically better and the other subjects.

Precisely, the applied questionnaire evaluation considers items regarding the (i) design and planning, (ii) management of the learning process, (iii) tuition and evaluation, (iv) review and improvement along with features of the (v) overall performance of the lecturer (such as transmission of ethical values and behaviors). There are some questions that can be used to evaluate the developed RSC and find out if the method resulted in positive results that were aligned with the research questions of the paper. These questions are:

1. Does the lecturer propose stimulating tasks? (STI)

2. Does the lecturer stimulate the generation of ideas? (GEN)

3. Does the methodology support the autonomy of the student? (AUTO)

4. Does the lecturer make students reflect on the learning experience? (LEARN)

These four questions were responded to by the five groups mentioned at the beginning of Section 2 . The students answered the questions by rating them with a score from 0 (minimum) to 5 (maximum). The feedback was used to compare the performance of the RSC implemented subjects with the ones not involving RSC. The ratings of each of the four questions (STI, GEN, AUTO, and LEARN) for the RSC implemented subject were compared with the respective average ratings of all the other non-RSC subjects, as shown in Table 1. We observed that in the case of all four questions, for five groups, the ratings of the RCS implemented subjects were higher than the average ratings of the other subjects where RSC was not used (except the first two questions of Class 2). In conclusion, the results showed that the RSC implemented subjects were overall better valued by students ( $90 \%$ of the cases) than the subjects using the traditional teaching methods.

Table 1. Descriptive statistic results of the evaluations of the subjects with and without RCS in them.

\begin{tabular}{ccccccccccc}
\hline & \multicolumn{2}{c}{ Class 1 } & \multicolumn{2}{c}{ Class 2 } & \multicolumn{2}{c}{ Class3 } & \multicolumn{2}{c}{ Class 4 } & \multicolumn{2}{c}{ Class 5 } \\
\hline & Av. S. & RCS Subj. & Av. S. & RCS Subj. & Av. S. & RCS Subj. & Av. S. & RCS Subj. & Av. S. & RCS Subj. \\
\hline STI & 336 & 4.17 & 3.75 & 3.25 & 3.76 & 4.22 & 3.50 & 3.65 & 3.28 & 4.55 \\
GEN & 3.39 & 4.00 & 3.51 & 3.82 & 3.75 & 4.22 & 3.43 & 3.59 & 3.52 & 4.09 \\
AUTO & 3.28 & 4.33 & 3.58 & 3.43 & 3.67 & 4.22 & 3.30 & 3.54 & 3.33 & 4.33 \\
LEARN & 3.35 & 4.25 & 3.36 & 3.53 & 3.52 & 4.33 & 3.36 & 3.81 & 3.29 & 4.55 \\
\hline
\end{tabular}

Av. S.: Average degree of the Semester. RCS Subj.: Subject with RCS.

In order to analyze the statistical significance of these data, it was possible to indistinctively apply the estimation of intervals or the analysis of variance (ANOVA). As the homoscedasticity (equality 
of variances) condition was not fulfilled, the technique to be applied had to consider unknown and unequal variances. In this case, the ANOVA for the difference between the average values for the results of each of the questions was applied. In the four questions, it was possible to conclude that the confidence levels of at least $90 \%$ that the RCS obtained significantly better results than the other subjects.

\section{Concluding Remarks}

Recently, new student-based learning methodologies have been developed to make the learning process less complicated and more effortless for students and to allow them to obtain new abilities and skills more conveniently. Project based learning (PBL) is one of these teaching methods in which students learn the concepts and principles by actively engaging in complex real-world problems, which can be incorporated easily into any learning case. This effective methodology enables students not only to develop profound content knowledge, but also creativity, critical thinking, communication, problem-solving, and collaboration skills.

RCS is a variant of the PBL methods that supports the PBLs by incorporating actual problems presented by and followed up by the personnel of companies who are conducting them. Although the literature about RCS is scarce, the theoretical advantages of the method are evident. Within this context, this research describes five implementation cases of the RCS as a lecturing method and evaluates its effectiveness statistically, obtaining statistically significant results. Both the quantitative and qualitative results obtained confirmed that RCS was significantly better than the average teaching methods. The results of the study demonstrate that applying RSC in engineering studies has the potential to move the field of engineering education forward. The students go beyond the level of only thinking ideas to confronting them with a real situation in a real industrial context. The student's journey along the learning process using the RCS method involves, under a specific industrial environment, a relationship with people with different roles such as lecturer, mentor, and company representative. This means many inputs and interactions that, together with the acquired knowledge and autonomous learning, generate a proper atmosphere to foster innovation. In fact, RCS explicitly links the research and education sides represented in this case by the universities, and the market side represented by the industry. It can play a key role in encouraging open innovation engineering in two ways. First, from a theoretical approach, incorporating open innovation in the curricula. Second, from a practical approach, RCS integrates different stakeholders from different positions of the knowledge funnel of open innovation engineering [32]. This method contributes to fostering talented people to boost innovation in fast changing and globalized markets.

There are two main limitations of this research: (i) the limited number of lecturers practicing the initiative and (ii) the reduced number of cases tested. For the first limitation, more subjects and lecturers should be involved in the development of the RCSs, as it is not possible otherwise to ensure that the improvement comes from the application of the specific methodology or from having lecturers that, on average, are quite good-performers. The second limitation remarks on the need for further testing to gain a more relevant statistical significance.

Thus, future research will be oriented to expand the use of the technique with the aim to obtain even higher statistical evidence to confirm the obtained results. Furthermore, it is essential to continue research in analyzing both the potential and limitations of initiatives such as RCS, PBL, and PjPBL in situations related to pandemics such as COVID-19. It is evident that the relationships between academia and industry have been transforming due to the necessities that have emerged with the pandemic. Recently, external industrial lecturers have been presenting courses mostly online, whereas only in the recent past were they delivering lectures face to face.

Author Contributions: A.G., writing, conceptualization, investigation and funding acquisition; T.A., writing, conceptualization and investigation; A.d.l.C., A.O.-Z. and E.A., conceptualization and investigation. All authors have read and agreed to the published version of the manuscript. 
Funding: This research was funded by the X. INNOVATION IN TEACHING CALL OF THE UNIVERSITY OF DEUSTO, project "Application and potential validation of the Real Case Solving methodology as method for relevant learning at the Faculty of Engineering", and by the BBK Foundation.

Acknowledgments: We would like to thank the editor of DYNA journal, Jose Maria Hernandez, for the support provided in one of the cases.

Conflicts of Interest: The authors declare no conflict of interest.

\section{Abbreviations}

$\begin{array}{ll}\text { RCS } & \text { Real Case Solving } \\ \text { PBL } & \text { Problem Based Learning } \\ \text { PjBL } & \text { Project Based Learning } \\ \text { ERP } & \text { Enterprise Resource Planning } \\ \text { BI } & \text { Business Intelligence } \\ \text { JCR } & \text { Journal Citation Reports } \\ \text { KPI } & \text { Key Performance Indicators } \\ \text { ER } & \text { Entity Relationship } \\ \text { SSCC } & \text { Pallet number } \\ \text { DES } & \text { Discrete Event Simulation } \\ \text { ANECA } & \text { National Agency for Quality Assessment and Accreditation of Spain } \\ \text { STI } & \text { If the lecturer proposes stimulating tasks } \\ \text { GEN } & \text { If the lecturer stimulates the generation of ideas } \\ \text { AUTO } & \text { If the methodology supports the autonomy of the students } \\ \text { LEARN } & \text { If the lecturer makes think of the learning experience } \\ \text { Av. S. } & \text { Average degree of the Semester } \\ \text { ANOVA } & \text { Analysis of variance }\end{array}$

\section{References}

1. Larmer, J.; Mergendoller, J.; Boss, S. A Proven Approach to Rigorous Classroom Instruction. In Setting the Standard for Project Based Learning; ASCD: Alexandria, VA, USA, 2013; pp. 18-22.

2. $\quad$ Barrows, H.S.; Tamblyn, R.M. Problem-Based Learning: An. Approach to Medical Education; Springer Publishing Company: New York, NY, USA, 1980; pp. 25-28.

3. Surif, J.; Ibrahim, H.; Mokhtar, M. Implementation of Problem Based Learning in Higher Education Institutions and Its Impact on Students' Learning. In Proceedings of the 4th International Research Symposium on Problem-Based Learning, Kuala Lumpur, Malaysia, 2-3 July 2013; pp. 66-73.

4. Zhang, Y.; Zhou, L.; Liu, X.; Liu, L.; Wu, Y.; Zhao, Z.; Yi, D. The Effectiveness of the Problem-Based Learning Teaching Model for Use in Introductory Chinese Undergraduate Medical Courses: A Systematic Review and Meta- Analysis. PLoS ONE 2015, 10, e0120884. [CrossRef] [PubMed]

5. Freeman, S.; Eddy, S.L.; McDonough, M.; Smith, M.K.; Okoroafor, N.; Jordt, H.; Wenderoth, M.P. Active learning increases student performance in science, engineering, and mathematics. Proc. Natl. Acad. Sci. USA 2014, 111, 8410-8415. [CrossRef] [PubMed]

6. Chen, C.H.; Yang, Y.C. Revisiting the effects of project-based learning on students' academic achievement: A meta-analysis investigating moderators. Educ. Res. Rev. 2019, 26, 71-81. [CrossRef]

7. Guo, P.; Saab, N.; Post, L.S.; Admiraal, W. A review of project-based learning in higher education: Student outcomes and measures. Int. J. Educ. Res. 2020, 102, 101586. [CrossRef]

8. Harun, N.F.; Yusof, K.M.; Jamaludin, M.Z.; Hassan, S.A.H.S. Motivation in Problem-based Learning Implementation. Procedia Soc. Behav. Sci. 2012, 56, 233-242. [CrossRef]

9. Sada, A.; Mohd, Z.; Adnan, A.; Audu, R. Effects of problem-based learning in teaching and learning of technical and vocational education and training. Int. J. Sci. Res. Publ. 2015, 5, 712-713.

10. Zaman, U.; Nawaz, S.; Nadeem, R.D. Navigating Innovation Success through Projects. Role of CEO Transformational Leadership, Project Management Best Practices, and Project Management Technology Quotient. J. Open Innov. Technol. Mark. Complex. 2020, 6, 168. [CrossRef] 
11. Jabarullah, N.H.; Hussain, H.I. The effectiveness of problem-based learning in technical and vocational education in Malaysia. Educ. Train. 2019, 61, 552-567. [CrossRef]

12. Gal, B.; Rubio, M.; Iglesias, E.; González, P. Evaluation of participatory teaching methods in undergraduate medical students' learning along the first academic courses. PLoS ONE 2018, 13, e0190173. [CrossRef] [PubMed]

13. Caldwell, S.B.; Gedeon, T.D. Boldly Going where no Higher Educators Have Gone Before: A Review of the 1st International Conference on Higher Education Advances, Valencia, Spain. Procedia Soc. Behav. Sci. 2016, 228, 348-355. [CrossRef]

14. Ampuero-Canellas, O.; Gonzalez-Del-Rio, J.; Jorda-Albinana, B.; Rojas-Sola, J.; Eric, J.I. Developing Learning Strategies Based on Research Projects. US-China Educ. Rev. A 2011, 2, 162-169.

15. Trkman, P.; Mccormack, K.; Valadares De Oliveira, M.P.; Ladeira, M.B. The impact of business analytics on supply chain performance. Decis. Support Syst. 2010, 49, 318-327. [CrossRef]

16. Sutopo, W.; Aqidawati, E.F. Learning a Supply Chain Management Course by Problem Based Learning: Case Studies in the Newspaper Industry. In Proceedings of the International Conference on Industrial Engineering and Operations Management, Bangkok, Thailand, 5-7 March 2019.

17. Rodrigues, A.N.; dos Santos, S.C. A framework for applying problem-based learning to Computing Education. In Proceedings of the 2016 IEEE Frontiers in Education Conference (FIE), Erie, PA, USA, 12-15 October 2016; pp. 1-7.

18. Bessa, B.R.; Santos, S.; Duarte, B.J. Toward effectiveness and authenticity in PBL: A proposal based on a virtual learning environment in computing education. Comput. Appl. Eng. Educ. 2019, 27, 452-471. [CrossRef]

19. Noor, N.A.M.; Alias, A.; Ariffin, K.; Bhkari, N.M.; Hashim, A.H.A. Employing the Problem-Based Learning Approach in Civil Engineering Education: The Highway Engineering Experience. In Proceedings of the Second International Conference on the Future of ASEAN (ICoFA) 2017-Volume 1; Mat, N.A., Mohd, Z.Z., Muhamad, N.S., Eds.; Springer: Singapore, 2019; pp. 519-528.

20. Zhang, J.; Xie, H.; Li, H. Improvement of students problem-solving skills through project execution planning in civil engineering and construction management education. Eng. Constr. Archit. Manag. 2019, 26, 1437-1454. [CrossRef]

21. Caldwell, E. The Project Based Learning Combined with Problem Solving Based Learning in Industrial Engineering Programs. In Proceedings of the International Conference on Industrial Engineering and Operations Management, Bangkok, Thailand, 5-7 March 2019.

22. Fernández-Ceniceros, J.; Sanz-García, A.; Antoñanzas-Torres, F.; Alía-Martínez, M.; Pernía-Espinoza, A. Microproject-based teaching/learning methodology focused on emerging technologies and international entities cooperation. In Proceedings of the 1st International Conferenceon Higher Education Advances, Valencia, Spain, 24-26 June 2015; Volume 6, pp. 311-318.

23. Goti, A.; De la Calle, A.; Oyarbide-Zubillaga, A.; Alberdi, E.; Torres, B.; Bacigalupe, A.; Unanue, I. Implementation of a Business Intelligence tool at DYNA journal for the analysis and improvement of its Impact Factor. DYNA Ing. Ind. 2020, 95, 482-486.

24. Parenteau, J.; Sallam, R.L.; Howson, C.; Tapadinhas, J.; Schlegel, K.; Oestreich, T.W. Magic Quadrant for Business Intelligence and Analytics Platforms, Gartner Research Notes. 2016; p. 82. Available online: https://www.gartner.com/en/documents/3200317/magic-quadrant-for-businessintelligence-and-analytics-p (accessed on 18 November 2018).

25. Shukla, A.; Dhir, S. Tools for Data Visualization in Business Intelligence: Case Study Using the Tool Qlikview. In Proceedings of the third International Conference on Information Systems Design and Intelligent Applications, Visakhapatnam, India, 8-9 January 2016; pp. 319-326.

26. Kerschberg, B. How Big Data and Business Intelligence are changing the manufacturing industry. Available online: https://hub.appirio.com/cloud-powered-blog/how-big-data-and-business-intelligence-arechanging-the-manufacturing-industry (accessed on 7 January 2020).

27. Goti, A.; De la Calle, A.; Gil, M.J.; Errasti, A.; Uradnicek, J. Aplicación de un sistema Business Intelligence en un contexto Big Data de una empresa industrial alimentaria. DYNA 2017, 92, 347-353. [CrossRef]

28. Goti, A.; Garcia-Sanchez, A.; Ortega-Mier, M.; Uradnicek, J. Optimization of reordering points: Realistic solution to an extensively studied, but poorly solved problem. DYNA 2010, 85, 473-479.

29. Narasimhan, R.; Swink, M.; Wook Kim, S. Disentangling leanness and agility: An empirical investigation. J. Oper. Manag. 2016, 24, 440-457. [CrossRef] 
30. Oyarbide-Zubillaga, A.; Goti, A.; Sanchez, A. Preventive maintenance optimization of multi-equipment manufacturing systems by combining discrete event simulation and multiobjective evolutionary algorithms. Prod. Plan. Control. 2008, 19, 342-355. [CrossRef]

31. Melachrinoudis, E.; Olafsson, M. A microcomputer cashier scheduling system for supermarket stores. Int. J. Phys. Distrib. Logist. Manag. 1995, 25, 34-50. [CrossRef]

32. Yun, J.J.; Kim, D.; Yan, M.R. Open Innovation Engineering-Preliminary Study on New Entrance of Technology to Market. Electronics 2020, 9, 1-10.

Publisher's Note: MDPI stays neutral with regard to jurisdictional claims in published maps and institutional affiliations.

(C) 2020 by the authors. Licensee MDPI, Basel, Switzerland. This article is an open access article distributed under the terms and conditions of the Creative Commons Attribution (CC BY) license (http://creativecommons.org/licenses/by/4.0/). 